Original Research Paper

\title{
Investigation of Sandwich Panel Under High Temperature Loading Using Finite Element Analysis
}

\author{
${ }^{1}$ Sajjad Sayyar Roudsari, ${ }^{1}$ Armaghan Shalbaftabar, ${ }^{2}$ Taher M. Abu-Lebdeh, \\ ${ }^{2}$ Ahmed Megri and ${ }^{2}$ Sameer A. Hamoush \\ ${ }^{1}$ Department of Computational Science and Engineering, \\ North Carolina A\&T State University, Greensboro, NC 27411, USA \\ ${ }^{2}$ Department of Civil, Architectural and Environmental Engineering, \\ North Carolina A\&T State University, Greensboro, NC 27411, USA
}

Article history

Received: 16-05-2020

Revised: 06-06-2020

Accepted: 01-07-2020

Corresponding Author:

Sajjad Sayyar Roudsari Department of Computational

Science and Engineering, North Carolina A and T State University, Greensboro, NC 27411, USA

Email: ssayyarroudsari@aggies.ncat.edu

\begin{abstract}
Structural and nonstructural members are always encountered with extreme loading conditions. In case of nonstructural members, the failure happens much sooner due to lack of load capacity. The nonstructural elements are not designed for structural loading conditions. However, they might be impacted to other loading types such as fire. In recent years, the use of 3D panel is one of the most common partitions in the world. In this research, the effect of fire on 3D panel partitions is presented. To achieve this goal, ABAQUS finite element software is employed to simulate the $3 \mathrm{D}$ panel. The 3D panel is embedded inside steel frame. In order to have an accurate result, two validations are performed including steel frame and the steel frame with 3D panel. In the study, 5 different fire loadings 200, 400, 600,800 and $1000^{\circ} \mathrm{C}$ are applied into the model. Results include loaddisplacement diagram and stiffness and ductility factors. The results indicated that as fire load increases, the stiffness and ductility factor are reduced.
\end{abstract}

Keywords: 3D Panel, Fire Loading, ABAQUS, Stiffness, Ductility, Concrete Damage Plasticity

\section{Introduction}

Structures are often subjected to extreme loading conditions such as seismic earthquake and may have defects or high rate temperature, flooding, etc., (Sayyar Roudsari et al., 2019a; 2020; 2019b; 2019c; Sohi et al., 2020). These structures may have internal and/or external partitions which play a vital role in structural design. The partitions can be designed to have the loading capacity such as masonry wall or it can be used as light weight nonstructural member such as 3D panel. In contrast to structural members, 3D panel usually designed without adequate loading capacity under extreme conditions. The 3D panel is not a structural member but it may help to reduce the weight of structure leading to less shear force (He and Hu, 2008; Long, 1977). Schaeffer (1993; Schubel, 2005) have studied sandwich panel loaded under low velocity impact loading condition. They use woven carbon sheets and PVC foam to construct the panel. The tests were performed as quasi-static with low rate impact and static loading conditions. They investigated the load-strain response for both conditions and the results showed that using quasi-static method is more accurate in predicting the damage and response of sandwich panel. Hamid and Fudzee (2013) investigated the performance of a sandwich panel subjected to seismic loading condition. They casted Insulated Sandwich Wall Panel (ISWP) with two boards and one core. The board was cement fiber while the core of the wall was made from polyurethane material. The quasi-static load was applied laterally and strength-drift data were recorded. Their results indicated that the cracks start propagating at the foundation and the aluminum channel frame was buckled. Poluraju and Appa Rao (2018) conducted experimental tests on squat 3D sandwich walls under both vertical and lateral loading conditions. Four walls were constructed. Samples were $1125 \times 1250 \mathrm{~mm}$ in dimension. The weld meshing reinforcements were considered in two walls and additional reinforcement was applied for two other specimens. The design criteria were validated with Europe- 8 and ACI-318 codes. Their results showed that using additional reinforcement can remarkably enhance the ultimate stiffness and strength. Crewe et al. (2018) conducted experimental tests on four sandwich panel walls which were made according to ISO 13784-1. The wall thickness was $100 \mathrm{~mm}$ with the dimension of $2.4 \times 3.6 \times 2.4$ as width, 
length and height, in order. The fire load was applied to the wall and increased with the time. In other word, the fire was applied to reach $100 \mathrm{~kW}$ within $10 \mathrm{~min}$. Then, it was increased to $300 \mathrm{~kW}$ in the next $10 \mathrm{~min}$. The modification factor and validation were also performed in their study. The results showed that the use of combustible insulation does not protect the wall very well. In some cases, it causes growing fire and expose in the large area. Many researchers have discussed the effect of material properties on sandwich panel, as well as the performance of the partitions such as 3D panel under seismic conditions (De Matteis and Landolfo, 2000; Krzyżak et al., 2016; Ravi, 2017). However, there are few studies regarding the sandwich panel under fire or high temperature condition. These researches were mainly focused on the effect of fire on the panel in terms of energy, the temperature growth and damage of the panel (Bonner et al., 2020; Cooke, 2004; Roudsari and Abu-Lebdeh, 2019; Smolka et al., 2013; Wang and Foster, 2017).

In this study, the sandwich panels are evaluated under five different high temperature loading conditions. ABAQUS software is employed to simulate temperature loading. The panel contains two concrete walls embedded with reinforcement and a foam. The loaddisplacement diagrams are carried out and analytical investigation including stiffness, ductility is discussed.

\section{Finite Element Model}

In this research, ABAQUS software is employed to model and analyze the sandwich panel. In the process, the validation is essential to perform the simulation. In order to validate the initial model, the sandwich panel is modeled using the sandwich panel proposed by Kabir et al. (2006). The wall has a dimension of $1200 \times 640 \times 140 \mathrm{~mm}$ as height, width and thickness, respectively. The wall was framed with two number of IPE120 as columns at each side and one IPE120 beam. The stiffeners are also used at the beam-columns joints. The mesh reinforcements were considered with 3.5 wires in each concrete wall. It should be noted that the panel is constructed with $40 \mathrm{~mm}$ thick foam sandwiched by concrete plates at each side of the wall. Figure 1, shows the schematic view of the sandwich panel. In Fig. 2, the geometry of sandwich panel is shown.

The ABAQUS software is used to simulate the validation model. Two different validations were performed. The first one was without inside wall while the second model included the wall. The concrete and foam were modeled with solid element (C3D8R). The beam and columns were created with shell element (S4R) and reinforcement was modeled by beam element (B31) (Fallahi et al., 2018). Additionally, the concrete compressive strength of $34.5 \mathrm{MPa}$ was used. The Concrete Damage Plasticity model (CDP) is used to define concrete behavior (Roudsari et al., 2019; Sayyar Roudsari et al., 2018; Soleimani et al., 2019; Soleimani and Sayyar Roudsari, 2015; 2019). The HyperFoam criteria is exploited to define the foam behavior. Therefore, $\mu 1, \alpha 1$ and $\nu 1$ are $0.5,2$ and 0.33 , respectively. The plasticity criteria are assigned for steel beam, columns and stiffeners. The yield and ultimate stress of steel were reported as 240 and $370 \mathrm{MPa}$, in order. Moreover, the yield and ultimate stress of the reinforcement wires were 4000 and $5200 \mathrm{MPa}$, respectively. Figure 3 displays the modeling of sandwich panel.

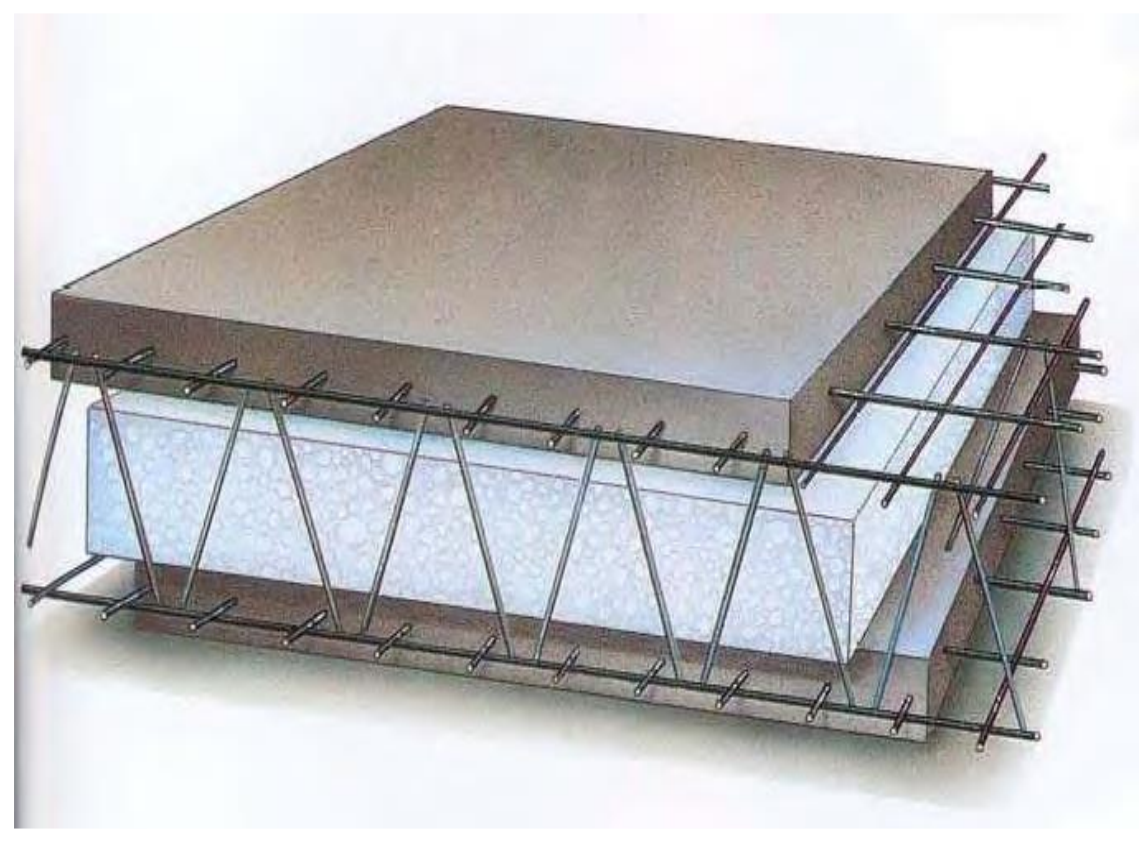

Fig. 1: Schematic view of sandwich panel (Kabir et al., 2006) 


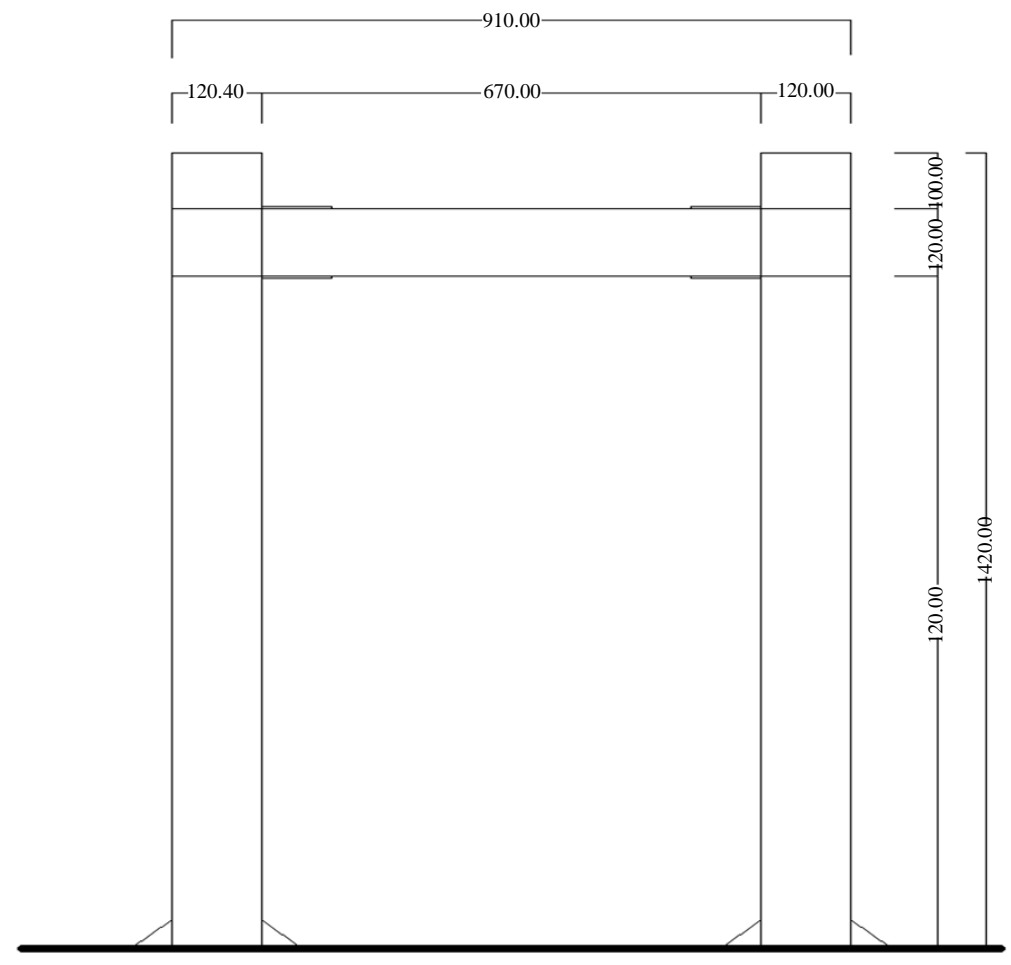

Fig. 2: Geometry of sandwich panel (Kabir et al., 2006)
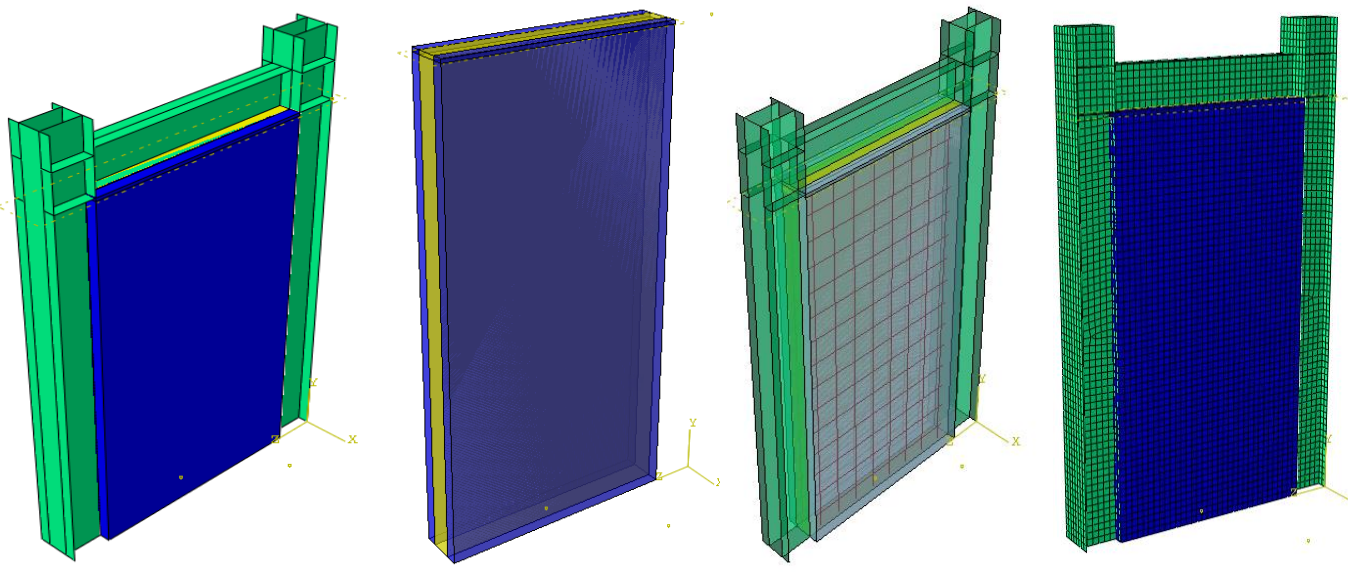

Fig. 3: Modeling of sandwich panel in ABAQUS

The interaction between wall and frame are considered to be "Tie" and wires are connected to the concrete with "Embedded Region". The sandwich panel was subjected to Non-Linear Static General analysis. The lateral load is assigned as "Displacement-Control" and the bottom surface are totally fixed (Us and URs are equal zero). After the analysis and obtaining the results, the two validations are compared. In Fig. 4 and 5, the validation of model without Sandwich Panel (S-0-WS) and model with sandwich panel (S-0-NS) are shown. In Fig. 4, the maximum load capacity for ABAQUS results $(66.35 \mathrm{kN})$ compared with experimental ones $(65.2 \mathrm{kN})$ shows $1.75 \%$ difference. In Fig. 5, the results of model with sandwich panel show $3.45 \%$ reduction of load capacity obtained by ABAQUS compared with experimental result.

After validating the model without and with sandwich panel accurately, the model with sandwich panel is employed to be evaluated under high temperature loading condition. Five different temperatures were chosen as 200 , 400, 600, 800 and 1000 Celsius Degree. The model's information is shown in Table 1. In this table, the S-0-NS indicates the model with no sandwich panel (only steel 
frame) and zero temperature. Also, S-0-WS demonstrates the model with sandwich panel without temperature loading. Other models are entitled with its temperature load. For instance, S-200 indicates the model of sandwich panel under $200^{\circ} \mathrm{C}$ loading condition. The modeling properties remain the same as used in the validation. However, the temperature criteria need to be defined in model development. The conductivity and specific heat of foam are 0.028 and 1300 , in order. The concrete conductivity is 0.0005 at $0^{\circ} \mathrm{C}$ and 0.00114 at each specific temperature. Also, the specific heat of concrete is assigned to be 1000 . The steel material has the specific heat of 5225 and the conductivity of 0.04 at $0^{\circ} \mathrm{C}$ and 0.0518 each specific temperature. The ASTM E119 (ASTM, 1990) standard is employed for applying the high temperature loading. The Coupled-Temp-Displacement (Transient) analysis is selected. The temperature room is considered $25^{\circ} \mathrm{C}$ and surface coefficient is 0.01 . The allowable temperature applies to be at most $10^{\circ} \mathrm{C}$. Figure 6 , shows the time-amplitude factor for finite element simulation. The vertical numbers are a factor of 1000 such as that 0.6 indicates $600^{\circ} \mathrm{C}$. Figure 7, displays the interaction (left side) and boundary condition (right side) of high temperature analysis.

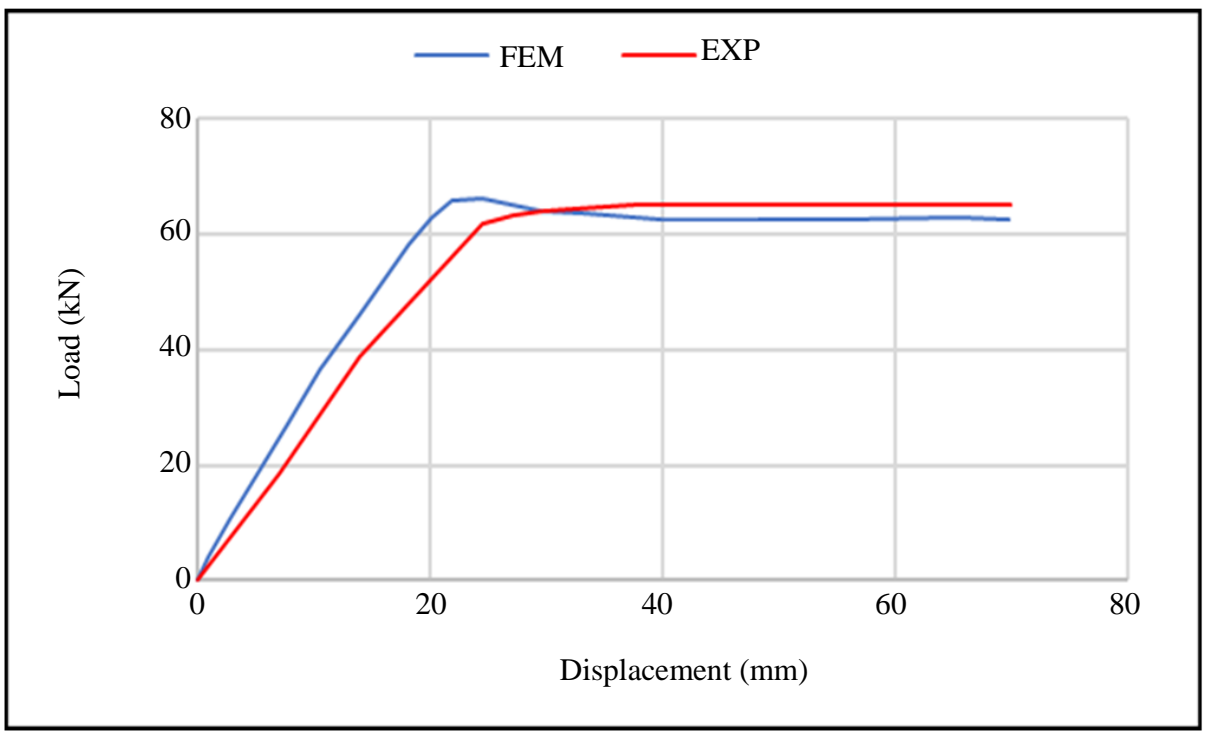

Fig. 4: Validation of experimental Vs ABAQUS for model without sandwich panel (S-0-NS)

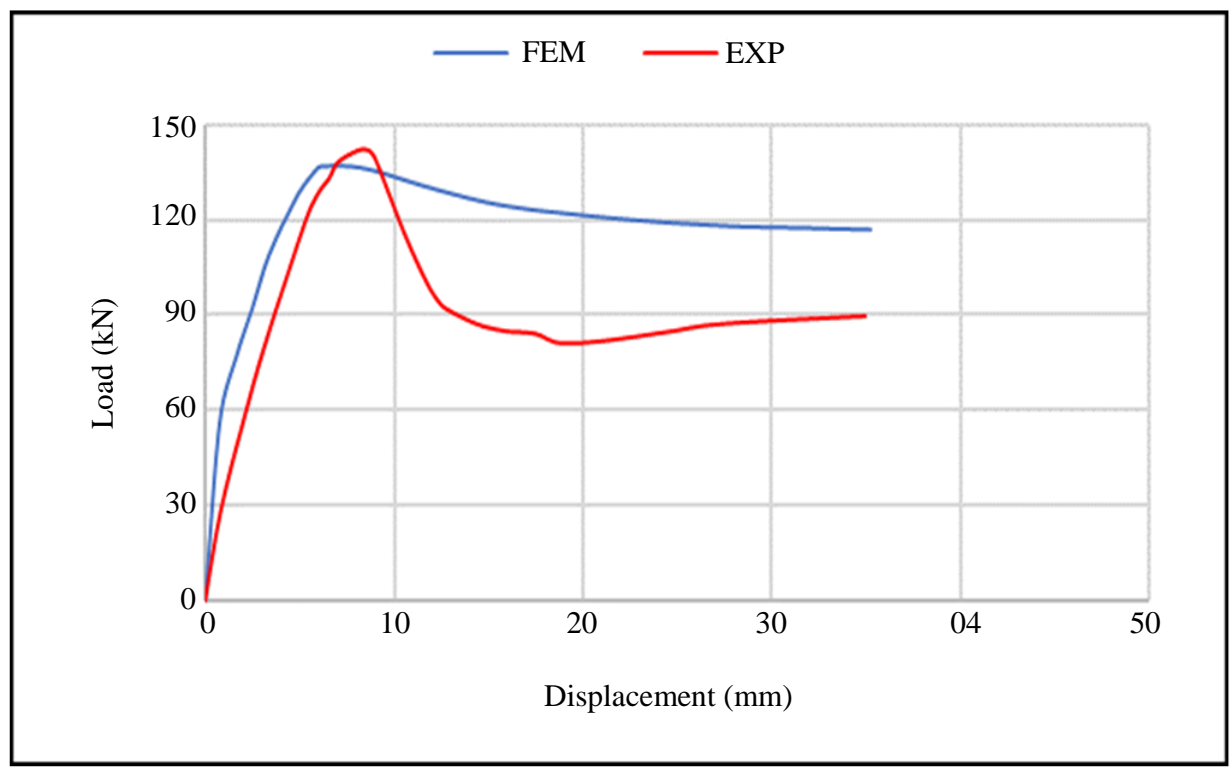

Fig. 5: Validation of experimental Vs ABAQUS for model with sandwich panel (S-0-WS) 


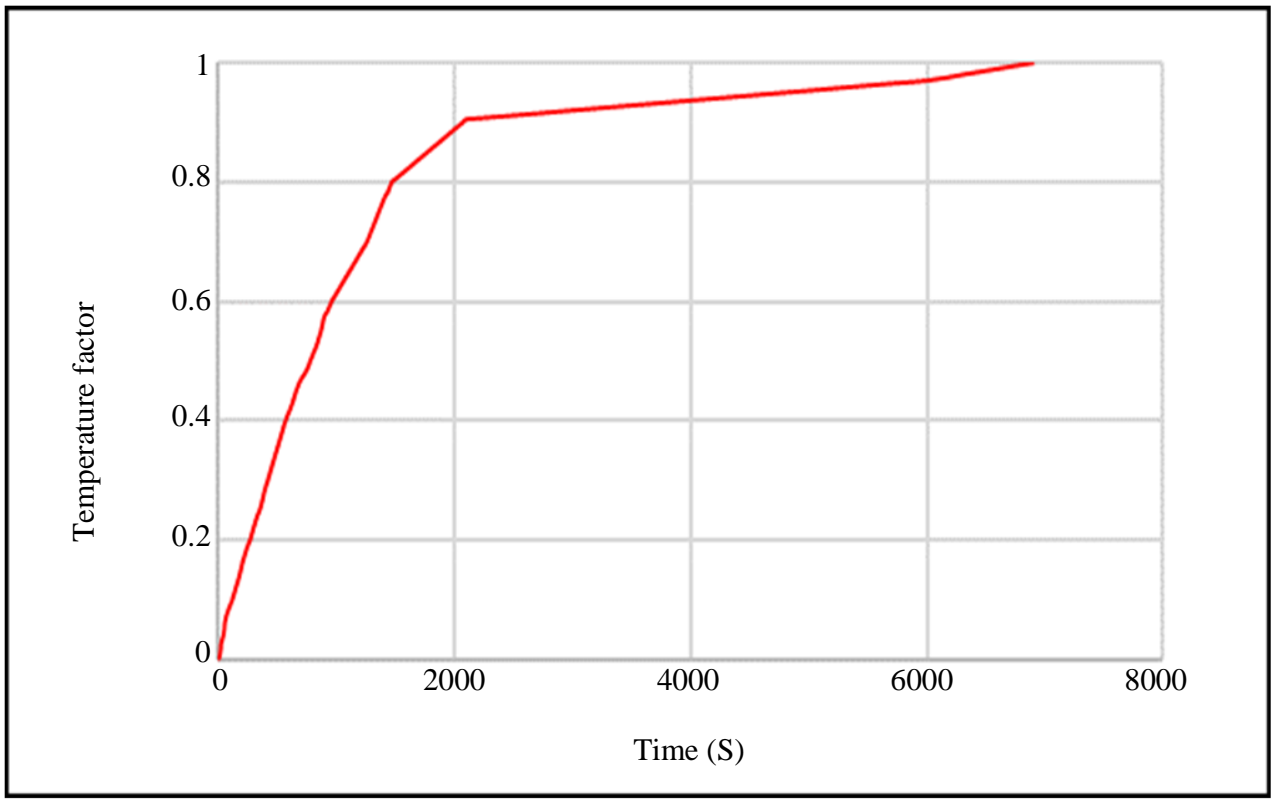

Fig. 6: Temperature-time amplitude (ASTM, 1990)
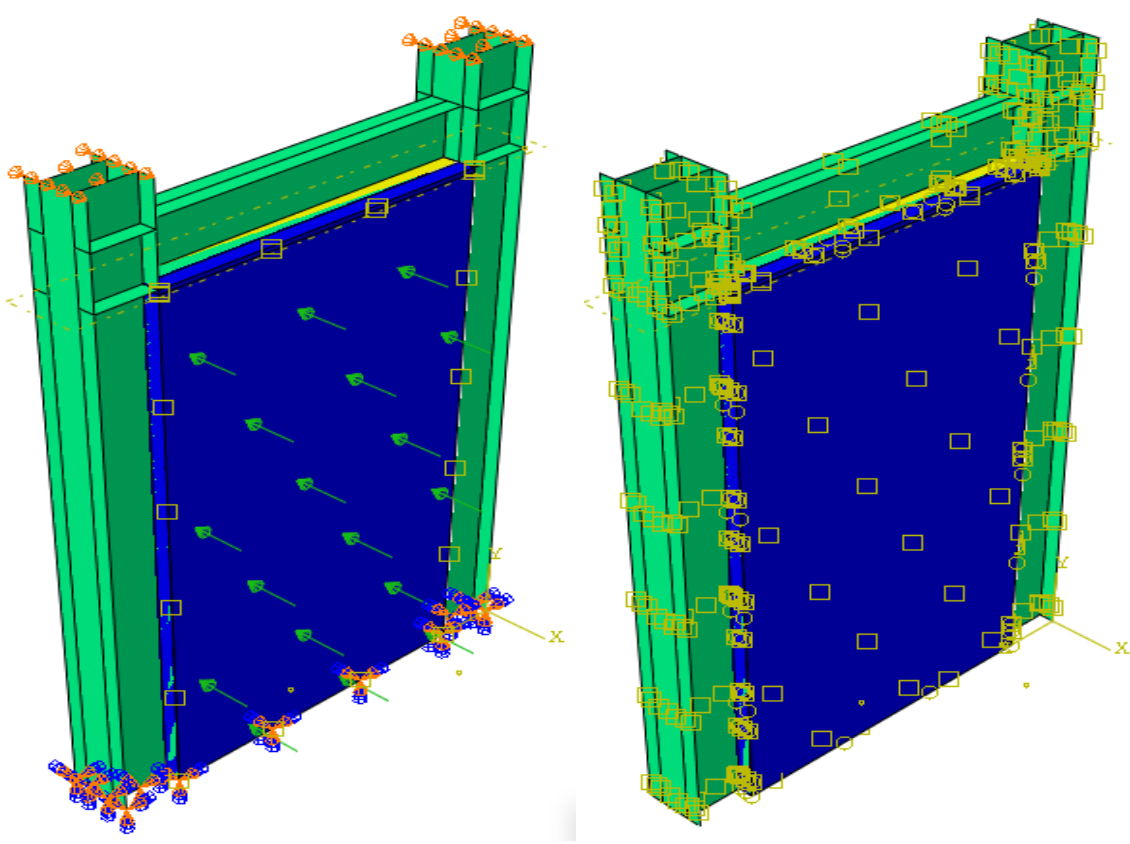

Fig. 7: The interaction and boundary condition of high temperature modeling

Table 1: Model's ID and information

\begin{tabular}{llllllll}
\hline Temperature $\left({ }^{\circ} \mathrm{C}\right)$ & 0 & 0 & 200 & 400 & 600 & 800 & 1000 \\
\hline ID & S-0-NS & S-0-WS & S-200 & S-400 & S-600 & S-800 & S-1000 \\
\hline
\end{tabular}

\section{Results and Discussion}

In this section, the load-displacement diagrams for specimens subjected to high temperature are shown in Fig. 8. As shown in this figure, the maximum load capacity for S-200, S-400, S-600, S-800 and S-1000 are $129.70,120.80,112.60,76.70$ and $54.80 \mathrm{kN}$, respectively. Comparing the load capacity of specimens subjected to high temperature with the reference specimen (without temperature (S-0-WS)) 
shows that increasing the temperature to $200^{\circ} \mathrm{C}$ (S200) causes $5.50 \%$ reduction in load capacity. Similarly, the reduction in load capacity was $12.00 \%$ for (S-400), $18.00 \%$ for (S-600), $44.00 \%$ for (S-800) and $60 \%$ for $(\mathrm{S}-1000)$. Furthermore, the reduction in the displacement at failure was $0.7,4.00,5.50,7.20$ and $15.30 \%$ for S-200, S-400, S-600, S-800 and S1000 , respectively.

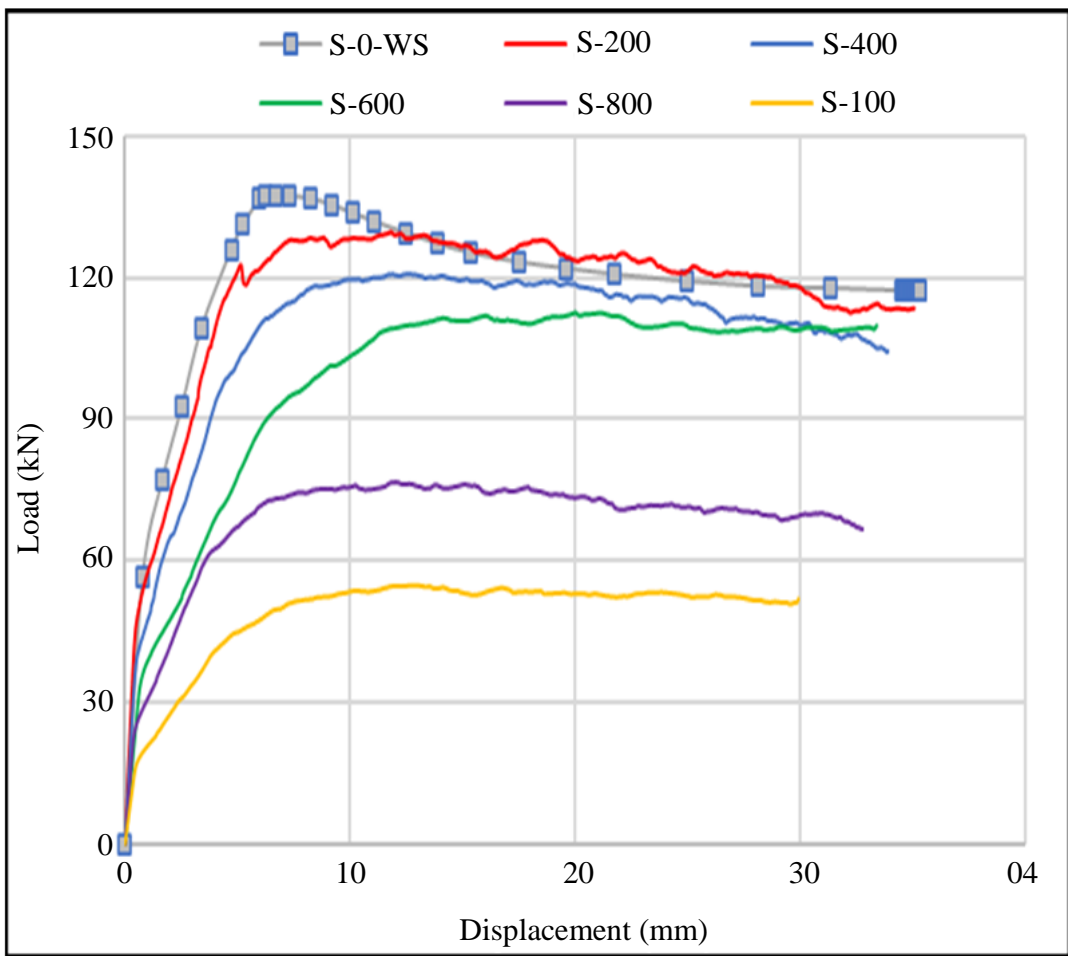

Fig. 8: Load-displacement diagrams for sandwich panel models

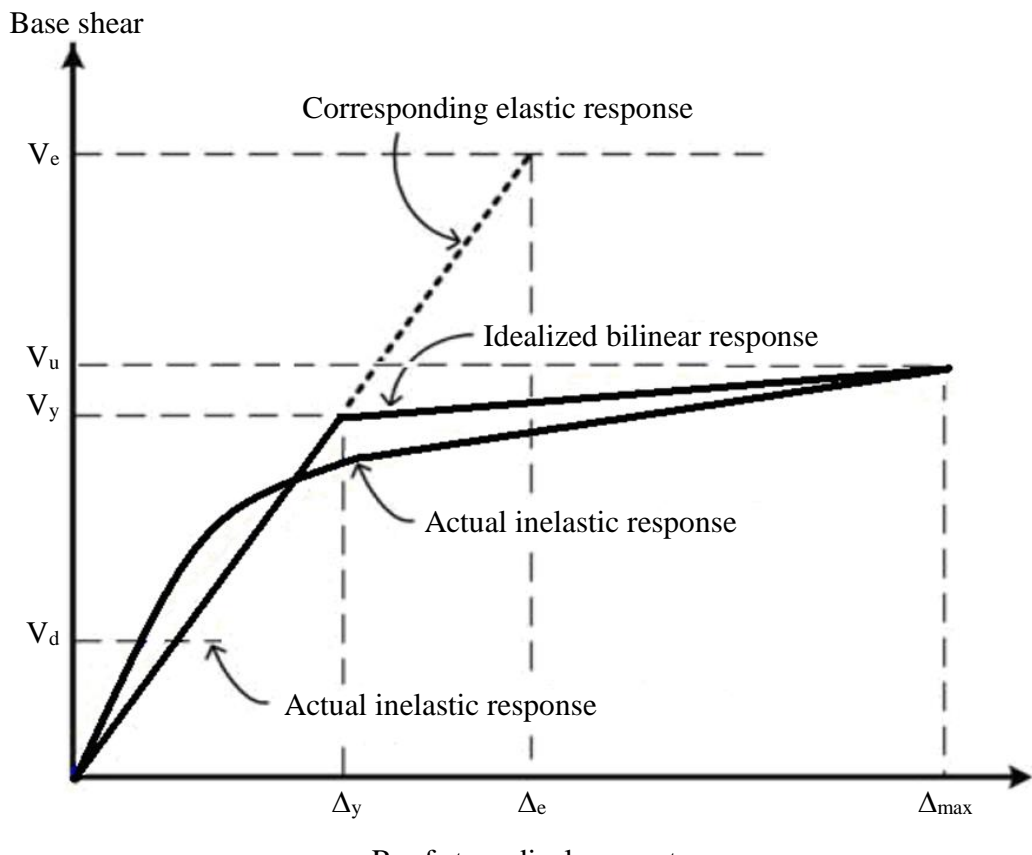

Roof story displacement

Fig. 9: Load Vs. displacement bilinear graph (Mahmoudi and Zaree, 2013) 
In order to evaluate the effect of temperature on the sandwich panel wall, the parametrical study is essential. In this sutdy, the parametrical investigation is focused on stiffness and ductility factors. Equations 1 and 2 show the stiffness and ductility factor. In these equations, $V_{y}, \Delta_{y}$ and $\Delta_{\max }$ are force at yield point, displacement at yield point and displacement at failure, in order. $E$ and $\mu$ are stiffness and ductility, respectively. Figure 9, shows the bilinear graph for the stiffness and ductility. These two factors are computed for all specimens and displayed in Fig. 10 and 11:

$E=V_{y} / \Delta_{y}$

$\mu=\Delta_{\max } / \Delta_{y}$

(ACI-Committee-201-1R-92, 1997).

In Fig. 10, the stiffness of S-0WS (model with sandwich panel without fire load) compared to S-0-NS (model without neither sandwich panel nor fire) enhanced about $782 \%$. It means that having the sandwich panel improved the stiffness from $3.53 \mathrm{kN} / \mathrm{mm}$ for S-0-NS to $27.6 \mathrm{kN} / \mathrm{mm}$ for S-0-WS. Also, the trend of stiffness reduction indicates that increasing the fire temperature reduces the stiffness of system. Comparing S-200 with S-0-WS demonstrates that 200 fire temperature causes $13.5 \%$ reduction of stiffness. Contrasting of S-1000 with S-0-WS model shows 67\% reduction of stiffness. However, the comparison of S1000 with S-0-NS declares that the stifnes of sandwich panel under 1000 Celsuis Degree has better performance than the model without sandwich panel (S-0-NS). Moreover, in Fig. 11, the ductility results show that the S-0-NS has only 3.88. Comparison of S0 -WS with S-200, S-400, S-600, S-800 and S-1000 indicates that the ductility reduction is about $5.8,20.7$, $24.5,32$ and $44 \%$. Comparisn the ductility of S-0-NS with S-1000 shows that having sandwich panel improved the ductility factor about $2 \%$.

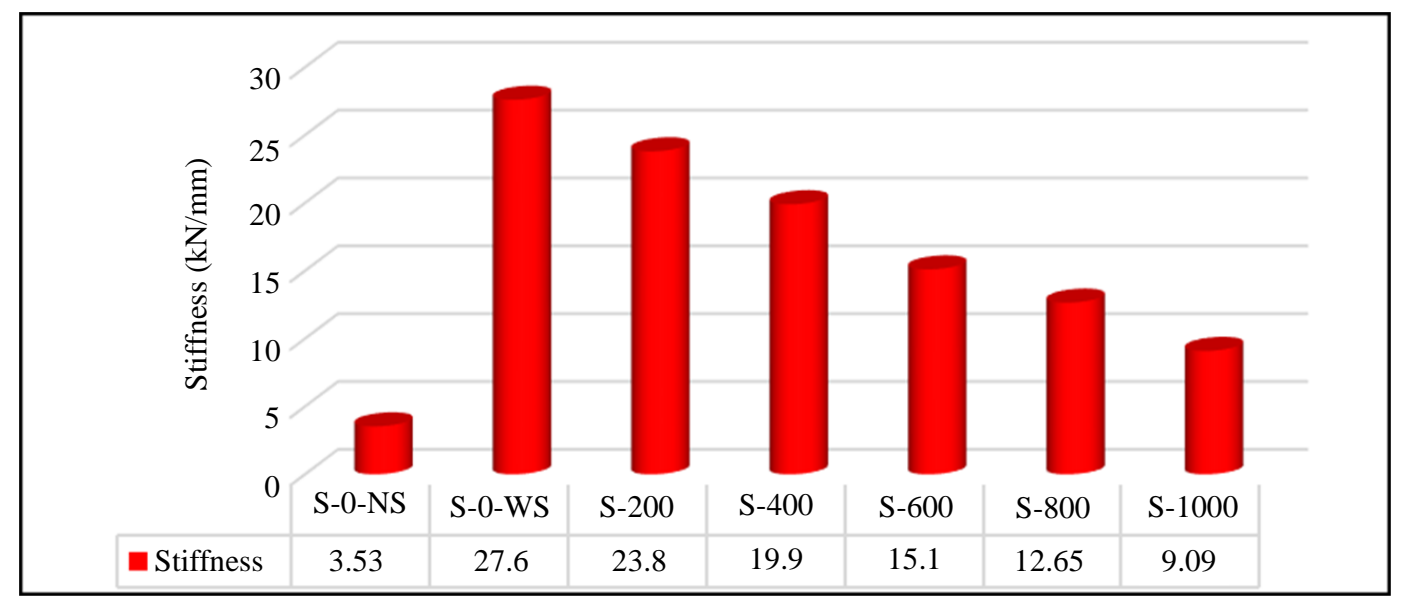

Fig. 10: Stiffness of models $(\mathrm{kN} / \mathrm{mm})$

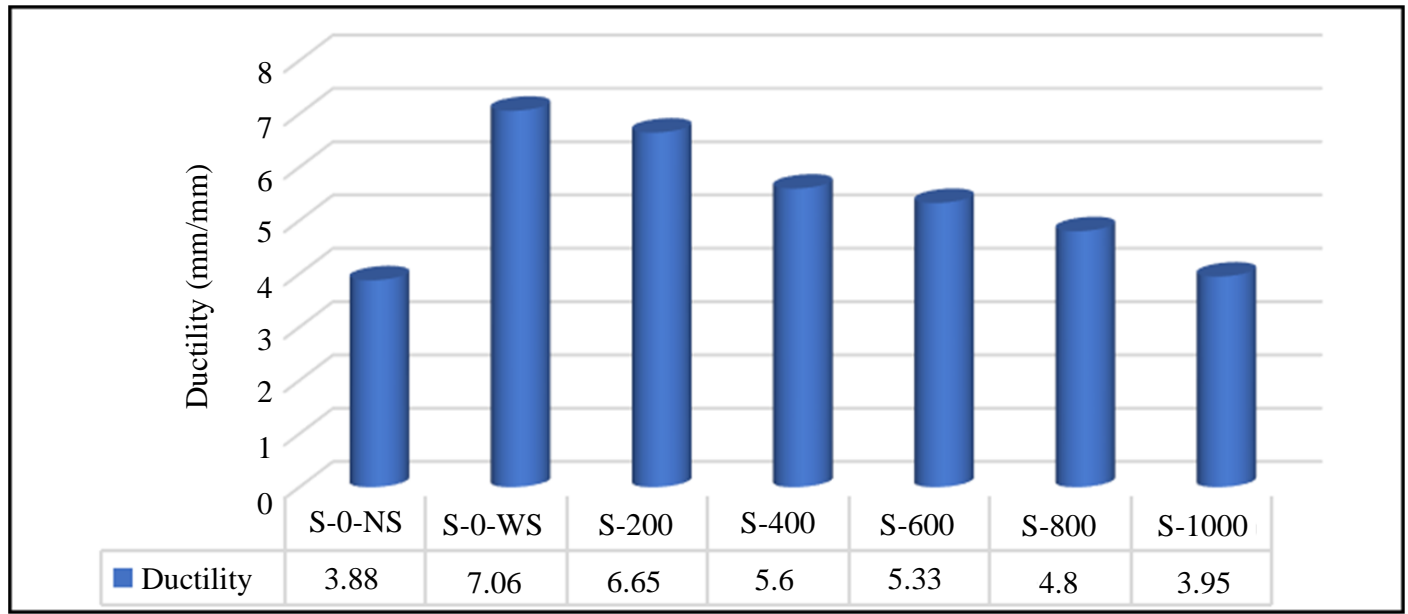

Fig. 11: Ductility of models $(\mathrm{mm} / \mathrm{mm})$ 


\section{Conclusion}

Based on modeling and simulation of this research, the following results are concluded:

- ABAQUS software can precisely predict the 3D panel behavior under fire loading conditions

- Adding 3D panel can enhance the load capacity compared with frame without 3D panel

- Increasing the fire load reduces the stiffness and ductility of 3D panel

- The load capacity and maximum displacement of 3D panel are also decreased by increasing the fire loading

\section{Acknowledgement}

The authors would like to thank the colleagues for the support and contributions.

\section{Author's Contributions}

Sajjad Sayyar Roudsari and Armaghan Shalbaftabar: Provided the research topic, performed modeling with ABAQUS software and data analysis. Also, participated in writing the manuscript.

Taher Abu-Lebdeh, Ahmed Megri and Sameer A. Hamoush: Guided the research development, finite element plan and data analysis. Also, participated in writing the manuscript.

\section{Ethics}

This article is an original research paper. There are no ethical issues that may arise after the publication of this manuscript.

\section{References}

ACI-Committee-201-1R-92, 1997. Guide for Making a Condition Survey of Concrete in Service. 1st Edn., American Concrete Institute.

ASTM, 1990. Standard Methods of Fire Test on Building Construction and Materials. 1st Edn., ASTM E119-88. Philadelphia, ASTM, USA

Bonner, M., W. Wegrzynski, B.K. Papis and G. Rein, 2020. KRESNIK: A top-down, statistical approach to understand the fire performance of building facades using standard test data. Buil. Environ., 169: 106540-106540.

DOI: 10.1016/j.buildenv.2019.106540

Cooke, G.M., 2004. Stability of lightweight structural sandwich panels exposed to fire. Fire Mater., 28: 299-308. DOI: 10.1002/fam.851
Crewe, R.J., J.P. Hidalgo, M.X. Sørensen, M. McLaggan and S. Molyneux et al., 2018. Fire performance of sandwich panels in a modified ISO 13784-1 small room test: The influence of increased fire load for different insulation materials. Fire Technol., 54: 819-852.

DOI: $10.1007 / \mathrm{s} 10694-018-0703-5$

De Matteis, G. and R. Landolfo, 2000. Diaphragm action of sandwich panels in pin-jointed steel structures: A seismic study. J. Earthquake Eng., 4: 251-275. DOI: 10.1080/13632460009350371

Fallahi, M., S. Sayyar Roudari, M. Haghighifar and R. Madandoost, 2018. Modeling of reinforced concrete frames with Infill walls under cyclic loading Strengthening with CFRP. Am. J. Eng. Applied Sci., 11: 1086-1099. DOI: 10.3844/ajeassp.2018.1086.1099

Hamid, N.A. and M.M. Fudzee, 2013. Seismic performance of Insulated Sandwich Wall Panel (ISWP) under in-plane lateral cyclic loading. Int. J. Emer. Technol. Adv. Eng., 3: 1-17.

$\mathrm{He}, \mathrm{M}$. and W. Hu, 2008. A study on composite honeycomb sandwich panel structure. Mater. Design, 29: 709-713.

DOI: 10.1016/j.matdes.2007.03.003

Kabir, M.Z., A.R. Rahai and Y. Nassira, 2006. Nonlinear response of combined system, 3D wall panels and bending steel frame subjected to seismic loading. WIT Trans. Built Environ.

Krzyżak, A., M. Mazur, M. Gajewski, K. Drozd and A. Komorek et al., 2016. Sandwich structured composites for aeronautics: Methods of manufacturing affecting some mechanical properties. Int. J. Aerospace Eng.

Long, W.G., 1977. Sandwich Panel Construction. 1st Edn., Google Patents.

Mahmoudi, M. and M. Zaree, 2013. Determination the response modification factors of buckling restrained braced frames. Proc. Eng., 54: 222-231.

DOI: $10.1016 /$ j.proeng.2013.03.020

Poluraju, P. and G. Appa Rao, 2018. Performance of squat 3D sandwich walls with longitudinal reinforcement and boundary elements under lateral cyclic loading. J. Sandwich Structures Mater., 20: 946-973. DOI: 10.1177/1099636216682546

Ravi, P.S.A., 2017. Seismic analysis of 3D sandwich panel wall building with varying soil strata in different zones. Int. J. Eng. Res. Technol., 6: 600-604. DOI: 10.17577/IJERTV6IS060268

Roudsari, S.S. and T.M. Abu-Lebdeh, 2019. Evaluation of fire effects on reinforced concrete columns using finite element method. Am. J. Eng. Applied Sci., 12: 227-235. DOI: 10.3844/ajeassp.2019.227.235 
Roudsari, S.S., S.A. Hamoush, S.M. Soleimani and R. Madandoust, 2019. Evaluation of large-size reinforced concrete columns strengthened for axial load using fiber reinforced polymers. Eng. Structures, 178: 680-693. DOI: 10.1016/j.engstruct.2018.09.071

Sayyar Roudsari, S., S. Hamoush, T. Szeto and S. Yi, 2019a. Using a 3D Computer Vision System for Inspection of Reinforced Concrete Structures. In: Advances in Intelligent Systems and Computing, Arai, K. and S. Kapoor (Eds.), Springer, ISBN-13: 9783030177980, pp: 608-618.

Sayyar Roudsari, S., T. Okore-Hanson, S. Hamoush and S. Younho, 2019b. Robotic non-destructive test of concrete structures with GPR, impact echo and 3D vision. Proceedings of the Paper Presented at the WM Symposia Conference, (WSC' 19), Phoenix, USA.

Sayyar Roudsari, S., T. Okore-Hanson, S.A. Hamoush, Y. Sun and M. Ahmed, 2019c. Robotic nondestructive evaluation of RC structures using 3D vision camera, IE and GPR. American Society for Nondestrctive.

Sayyar Roudsari, S., S. Hamoush, S. Soleimani, T. AbuLebdeh and M. HaghighiFar, 2018. Analytical study of reinforced concrete beams strengthened by FRP bars subjected to impact loading conditions. Am. J. Eng. Applied Sci., 11: 407-425.

DOI: 10.3844/ajeassp.2018.407.425

Sayyar Roudsari, S., T. Okore-Hanson, S. Hamoush, S. Yi and S. Younho, 2020. GPR robotic assisted non-destructive evaluation of concrete structures. Proceedings of the WM Symposia, (WMS' 20), Phoenix, AZ.

Schaeffer, B.C., 1993. Lightweight Sandwich Panel. 1st Edn., Google Patents.
Schubel, P.J.J.I.M.D., 2005. Low velocity impact behavior of composite sandwich panels. Compos. Part A: Applied Sci. Manufact., 36: 1389-1396. DOI: 10.1016/j.compositesa.2004.11.014

Smolka, M., B. Messerschmidt, J. Scott and B. Le Madec, 2013. Semi-natural test methods to evaluate fire safety of wall claddings. Proceedings of the MATEC Web of Conferences, (MWC' 13).

Sohi, A., S.S. Roudsari, S.A. Hamoush, and A.C. Megri, 2020. Influence of void's sizes and locations on the concrete compressive strength. Proceedings of the Third European and Mediterranean Structural Engineering and Construction Conference, (ECC' 20), Cyprus.

Soleimani, S.M. and S. Sayyar Roudsari, 2015. Analytical study of reinforced concrete beams tested under impact loading. Proceedings of the 4th International Workshop Performance Protection Strengthening Structures Under Extreme Loading, (UEL' 15), East Lansing, MI, USA.

Soleimani, S.M. and S. Sayyar Roudsari, 2019. Analytical study of reinforced concrete beams tested under quasi-static and impact loadings. Applied Sci., 9: 2838-2838. DOI: 10.3390/app9142838

Soleimani, S.M., A.J. Boyd, A.J. Komar and S.S. Roudsari, 2019. Fatigue in concrete under low-cycle tensile loading using a pressure-tension apparatus. Applied Sci., 9: 3217-3217. DOI: 10.3390/app9163217

Wang, Y. and A. Foster, 2017. Experimental and numerical study of temperature developments in PIR core sandwich panels with joint. Fire Safety J., 90: 1-14. DOI: 10.1016/j.firesaf.2017.03.003 